\title{
Anxiety through the Three Trimesters of Pregnancy
}

\author{
Amal A. Moussa, Lecturer \\ Psychiatric Nursing and Mental Health, Faculty of Nursing, Damanhour University
}

\author{
Anwaar A. Tayel, Lecturer \\ Obstetric and Gynecologic Nursing, Faculty of Nursing, Damanhour University
}

\begin{abstract}
Pregnancy is a major physical, psychological and social event in women's life. However, instead of being a joyful and exciting time, pregnancy may become a worrisome event in some women consequently, aggravating their morbidity. Objective: To assess anxiety through the three trimesters of pregnancy, in addition to the identification of some associated factors. A cross sectional descriptive research design was used to conduct this research. Setting: The present study setting included the three available Maternal and Child Health Care Centers affiliated to Ministry of Health and Population in Damanhour city, Al-Behaira Governorate. Subjects: a convenient sample of 300 pregnant women was recruited. Tools: two tools were used to collect the data (Socio demographic data and reproductive history and State Anxiety Inventory (SAI)). Results: The anxiety was present among $62.7 \%$ of the study subjects and level of anxiety is higher among pregnant women during first trimester followed by third trimester of pregnancy. Factors independently associated with anxiety included: unwanted pregnancy, presence offamily problems, age, educational level and extended family type. Conclusion: It can be concluded that, anxiety was experienced by nearly two thirds of the study subjects and the first trimester pregnant women had the highest anxiety level followed by third trimester. Recommendations: screening to detect anxiety symptoms must be done in antenatal care service and special attention should be given to the high risk pregnant women.
\end{abstract}

Keywords: Pregnant women, anxiety, and three trimesters of pregnancy.

\section{Introduction}

Pregnancy is a time of enjoyment and fulfillment for women ${ }^{(1)}$. It has both positive and negative impact on women depending on an individual vulnerability. While it is a period of growth and hope, it is also a period of changes in physiological, psychological and social perspectives in the pregnant women. Such changes can lead to emotional instability and increase in anxiety level ${ }^{(2,3)}$. Thus pregnancy is a potential stressor and a high-risk period during which women with psychological vulnerability may develop mental health problems. Although mild symptoms of stress and anxiety in response to this challenge are expected, a significant proportion of pregnant women manifest symptoms of anxiety which may progress and develop into clinical anxiety disorders ${ }^{(4)}$. It is reported that the most commonly seen psychological problems during pregnancy are anxiety and anxiety disorders ${ }^{(5)}$.

Anxiety can be defined as "a state of feeling uneasiness, uncertainty, or dread resulting from a real or perceived threat whose actual source is unknown or unrecognized". It has behavioral, emotional, cognitive, and physical symptoms ${ }^{(6,7)}$. There are two types of anxiety, the first one is trait anxiety which refers to a general level of stress that characterize an individual, and it is related to the personality. People with high levels of trait anxiety are often become quite easily stressed and anxious. The second type of anxiety is called a state anxiety that is often associated with a state 
of heightened emotions that develop in response to a fear or danger of a particular situation. High level of state anxiety can contribute to a degree of physical and mental dysfunction and affect the performance of several tasks ${ }^{(8)}$.

Evidence indicates an increase in psychiatric morbidity particularly anxiety during pregnancy ${ }^{(5)}$. Yonkers et al. (2001) reported that the prevalence of ante partum anxiety symptoms (AAS) is $24 \%$ among the pregnant women $^{(9)}$. A community-based study was conducted on pregnant women in an urban community in Pakistan found that $18 \%$ were anxious and depressed ${ }^{(10)}$. Another study conducted by Heron et al. (2004) on pregnant women reported that $21.9 \%$ of their subjects had anxiety symptoms and out of them, $64 \%$ continued to have anxiety postnatally ${ }^{(11)}$. Furthermore, the prevalence of state and trait anxiety symptoms among pregnant women was reported to be $59.5 \%$ and $45.3 \%$, respectively ${ }^{(12)}$.

In fact, the reported prevalence of anxiety symptoms during pregnancy varies among studies results. In a study conducted by Lee et al. (2007) 54\% of the women had antenatal anxiety during at least one trimester ${ }^{(13)}$. Estimated anxiety in the 2nd pregnancy trimester was found to be low in a previous study, it ranges from $6.6 \%$ to about $15 \%^{(14)}$. Anxiety levels seem to be higher in the 1st and 3rd trimesters, when compared with the 2 nd pregnancy trimester. A non linear pattern for anxiety has been pointed out in women, with the 1st and 3rd pregnancy trimesters being identified as high risk periods ${ }^{(13)}$. Furthermore, the prevalence of anxiety symptoms during pregnancy seems to be higher than in other periods of a woman's life ${ }^{(15-17)}$. A study by Buist et al. (2011) reported a higher anxiety level during the third trimester $(29.2 \%)$ as compared to postpartum period $(16.5 \%)^{(18)}$.

Women in developing countries continue to face very high risks of death and disability as a result of pregnancy; they are expected to have higher rates of anxiety during pregnancy compared to developed countries. This higher prevalence has been ascribed to be correlated to psychosocial and socio-demographic factors, including high exposure to stressful life events, e.g. childhood trauma, poverty, and low socioeconomic status ${ }^{(19-22)}$.

Speaking about the sources of anxiety during pregnancy, it was documented that the pregnant woman suffers from anxiety about her baby, her own health, as well as the changes that will happen in her life after birth. Heavy maternal duties and ambivalent feelings of vitality on one side and anxiety on the other side create instability of the mood in the pregnant woman. Several studies revealed that a relatively large group of women have a great fear of pregnancy and delivery, they are constantly in fear to imagine a hard and abnormal labor or their baby will be dead due to birth defects or other diseases ${ }^{(23-27)}$.

A study was conducted about the experiences of fears associated with pregnancy and childbirth had reported that, 78 percent of the studied pregnant women expressed fears related to pregnancy, to childbirth, or to both ${ }^{(28)}$. On the same line, another study had reported that the most common fears associated with pregnancy and childbirth was concern about course of pregnancy and childbirth and the baby's well-being ${ }^{(29)}$. Moreover, women's mood during pregnancy may change due to other factors such as a desire to have a fetus with particular sex, or the lack of interest to be pregnant and have other kids ${ }^{(3,23)}$.

Demographic characteristics such as marital status, age and educational level seems to play a role as a significant risk factors for anxiety symptoms during pregnancy $^{(4)}$. Results of a previous study showed that, those who are younger than 20 years old are considered high risk group for increased anxiety level during pregnancy and the less educated ladies suffer more from anxiety ${ }^{(30)}$. On the same line, the women's literacy showed strong associations with antenatal anxiety ${ }^{(1)}$. 
Concerning psychosocial risk factors for anxiety symptoms during pregnancy, the quality of marital relationship plays an important role in this issue. It is well documented that, women suffering from marital problems are more likely to report higher level of anxiety symptoms during pregnancy $^{(1,31)}$. On the contrary, the well adjusted couples are more likely to have equal attitude toward pregnancy and family formation, thus they are more likely to support each other in the pregnancy and the expectant mother is less likely to manifest antenatal anxiety symptoms ${ }^{(4)}$. These findings reflect the observations of other researchers that family/social support during pregnancy plays a significant role in predicting women's emotional status in the ante-partum period $^{(1,32)}$.

Attitude toward pregnancy is another significant risk factor for anxiety. Pregnant women with unwanted pregnancy have more difficulties in accepting the fact of pregnancy as well as adjusting themselves to their maternal role which might increase their tension and fear in response to dramatic challenges and changes resulting from pregnancy ${ }^{(4,33)}$. Previous studies findings indicate that wanting the baby and feeling positively about the pregnancy are strongly related to lower perceived anxiety at all stages of the pregnancy ${ }^{(33,34)}$.

Furthermore, women who had problems with previous pregnancies may be more likely to experience anxiety as well as women with previous miscarriages. A woman with a history of pregnancy loss showed higher levels of anxiety during their subsequent pregnancy than women without prior loss. Studies conducted on this issue indicated that, compared to women without spontaneous abortions, women with prior spontaneous abortion had higher levels of pregnancy-related fear and state anxiety during the first trimester ${ }^{(35-37)}$. In addition, anxiety can also be aggravated by external stresses, such as lack of resources or work responsibilities; women who are vulnerable or disadvantaged may have particular anxieties about their safety or basic needs for suitable housing and adequate income $e^{(36,38)}$.

Although antenatal anxiety is prevalent during pregnancy and a recent study reported that antenatal anxiety symptoms were more prevalent than antenatal depressive symptoms, research attention in the area of reproductive mental health has mainly focused on postpartum depression. Even studies on antenatal psychiatric disorders are mainly on antenatal depression. Much less attention has been given to anxiety symptoms among pregnant women ${ }^{(4)}$. Also, there is lacking of a reliable estimate about the proportion of pregnant women who feel anxiety that is intrusive and interferes with their daily activities, or who is exposed to substantial or chronic stresses while pregnant ${ }^{(36)}$.

\section{Aim of the Study}

This study aimed to assess anxiety through the three trimesters of pregnancy. Also, to identify the effect of some associated socio-demographic and reproductive factors on anxiety levels.

\section{$\underline{\text { Research Questions: }}$}

- Are there any differences of anxiety through the three trimesters of pregnancy?

- Is there any relation between socio demographic data and reproductive history and the presence of anxiety?

\section{Materials and Method}

\section{Materials}

Design: A cross sectional descriptive design was used.

Settings: The study was conducted at the three available Maternal and Child Health Care Centers affiliated to Ministry of Health and Population in Damanhour city, Albehaira Governorate namely, El Helal El 
Teby $\mathrm{MCH}$ center, Shobra MCH center and Abo Elresh MCH center.

Subjects: Using a power of $90 \%$ to detect the prevalence of ante partum anxiety symptoms $=29 \%$ with a precision of $10 \%$, $\alpha=5 \%$. The minimal required sample size was found to be 290 pregnant females. The sample size was calculated using EPI-INFO software. Thus, it was decided in the present study to recruit a convenience sample of 300 pregnant women; by using equal allocation method one hundred subjects were taken from each maternal and child health care center. Within each center it was emphasized that the one hundred subjects were almost equally distributed among the three pregnancy trimesters. Subjects were chosen according to the following criteria:

- Willing to participate in the study.

- Normal pregnancy course.

- No evidence of any complications or disease associated with pregnancy.

\section{Tools:}

\section{Tool I: Socio demographic data and reproductive history}

This tool was developed by the researchers and composed of two parts

Part 1: Socio-demographic data such as: age, marital status, level of education, and occupation.

Part 2: Reproductive history such as gravidity, parity, number of abortions or still birth, and weeks of gestation.

\section{Tool II: State Anxiety Inventory (SAI)}

This is one draft of the State-Trait Anxiety Inventory (STAI) developed by spielberger $1983^{(39)}$. The scale has been adopted, translated into Arabic language, validated, reliability tested and standardized on different Egyptian subjects by AbdelKhalek (1989) its test-retest reliability ranged between $0.82-0.91^{(40)}$. The inventory measures the situational anxiety and contains 20 items with four-point likert type scale that ranges from "one" for not anxious at all to "four" that reflects severe anxiety. A cutoff score $45 / 46$ was used to categorize anxious (score $\geq 45$ ) or not-anxious (score <45) states $^{(1)}$.

\section{Method}

- Permissions from the general administration of maternity and child care, Ministry of Health and Population in Cairo was obtained as well as the director of maternity and child health care centers after explanation of the purpose of the study.

- Tool I was developed by the researchers after review of relevant and recent literature.

- A pilot study was carried out on 30 pregnant women, excluded from the study subjects to ascertain the clarity and applicability of the tool as well as to detect any problem peculiar to the statements and estimate the time needed to complete the tools.

- Data were collected through an individual interview conducted in total privacy.

- The researchers interviewed the pregnant women who attend $\mathrm{MCH}$ centers. Each interview lasted about 15-20 minutes.

- The researchers revised the collected data from each maternal and child health care center to make sure that it represent the three trimesters of pregnancy.

- Data collection started from January to April 2014.

\section{Ethical considerations:}

The purpose of the study was explained to each pregnant women and verbal consent to participate in the study was obtained. Privacy was maintained during process of data collection and confidentiality of the collected data was ensured. 


\section{Statistical Analysis}

After data were collected it was revised, coded and fed to statistical software SPSS (Statistical Package for Social Science) version 18. The given graphs were constructed using Microsoft excel software. All statistical analysis was done using two tailed tests and alpha error of 0.05 . P value less than or equal to 0.05 was considered to be significant. The overall prevalence of anxiety was calculated and all risk factors were studied by calculating the crude odds ratio (the magnitude of effect of each studied risk factor) then adjusted odds ratio was calculated using binary logistic regression analysis to identify the unique effect of each factor after controlling the others.

\section{Results}

According to figure (1), $62.7 \%$ of the subjects were anxious and only $37.3 \%$ were not anxious

Table (1) exhibits that teenage pregnant women were equally anxious $(50 \%)$ or not anxious $(50 \%)$. Unlike those in their twenties, where the percent of the anxious ones $(63.1 \%)$ almost doubled that of the not anxious ones $(36.9 \%)$. With advanced age (thirties) about three-fourths (70.2\%) of them were anxious with statistical significance difference (P-value < 0.05).

Regarding educational level, the highest percent of anxiety (83.8\%) was among pregnant women with basic education. On the contrary, the lowest percent of anxiety (45.8\%) was observed among subjects with university education with statistical significance difference ( $\mathrm{p}$-value $<0.05$ ).

Nearly two-thirds $(68.4 \%)$ of the pregnant women who lived in extended families had an increased anxiety level compared to $56.8 \%$ from those who lived in simple families with statistical significance difference $(\mathrm{P}$-value < 0.05).

According to table (2) the first trimester pregnant women had the highest level
$(69.0 \%)$ of anxiety followed by third trimester $(60.0 \%)$ while the second trimester considered as a protective factor against anxiety $(59.0 \%)$ with statistical significance difference (P-value < 0.05$)$.

The majority $(86.4 \%)$ of multipara (three times or more) were anxious compared to only $53.8 \%$ of primipara with statistical significance difference ( $\mathrm{P}$-value $<0.05$ ). Again, the majority $(87.5 \%)$ of women with unwanted pregnancy were anxious with statistical significance difference (P-value < 0.05). Finally, the presence of family problems during pregnancy seemed to increase level of anxiety as shown where as much as $83.7 \%$ of the pregnant women with family problems were anxious more than pregnant women without family problems with statistical significance difference $(\mathrm{P}-$ value < 0.05).

Table (3) shows that, age, level of education, family type, months of pregnancy, parity, unwanted pregnancy and family problems were associated with anxiety with statistical significance difference (P-value < 0.05).

After putting these seven significant variables into a stepwise logistic regression model in the same table, only five independent factors of anxiety were consider the most important one which are; unwanted pregnancy, family problems, age, education and extended family.

\section{Discussion}

Pregnancy may be regarded as a crisis period during which new and different roles are necessary to be adapted. Several studies reported that pregnancy is at the top of the list of stressful events in women's life ${ }^{(5,11)}$. They may demonstrate different emotional reactions like acceptance, resistance or fear, anxiety, depression as a psychological reaction during pregnancy in the face of stress depending on the behavioral patterns and personal or mental characteristics ${ }^{(41,42)}$. Relatively little attention has been paid to 
antenatal mental health problems specifically antenatal anxiety.

The present study aimed to assess anxiety through the three trimesters of pregnancy. Beside to the identification of some associated socio demographic and reproductive variables. Findings of the present study showed that anxiety was present among nearly two thirds of the total studied subjects. This was expected because pregnancy is considered as a period full of stressors, physical and psychological changes, a lot of worries about the baby and mother's health, fear from responsibility, worries about delivery and expected complication and so on. This finding is consistent with a previous study conducted by Faisal-Cury et al. (2007) about the prevalence of anxiety and depression during pregnancy in a private setting sample which reported that, the prevalence of state and trait anxiety symptoms was $59.5 \%$ and $45.3 \%$ respectively among their pregnant subjects $^{(12)}$.

Moreover, significant changes were observed in anxiety symptoms throughout pregnancy. Symptoms of anxiety followed a $\mathrm{U}$ pattern in pregnancy, being higher at the $1^{\text {st }}$ trimester, registering a decrease in the $2^{\text {nd }}$ trimester and an increase in the 3rd one. These results are in agreement with what is stated in the relevant literatures about first trimester of pregnancy as a period of great stress because of multiple physiological and psychological changes that occurs during this period and the third trimester as a time of anticipation of delivery that may be associated with increase level of anxiety. Moreover, the literature of psychological adjustment to pregnancy pointed to the 2 nd trimester as a period of higher stability after the turbulence of the initial adaptation and prior to the stress of partum anticipation $^{(13,16)}$. The findings of previous study conducted by Hussein SH (2006) to determine the frequency of anxiety among Sudanese women found that anxiety level increases with time in the studied group being $30.1 \%$ in first trimester, $10.7 \%$ in second trimester and $60 \%$ in third trimester in contrast to the control group ${ }^{(30)}$.

The present study revealed a statistically significant difference between maternal age and level of anxiety, as the women's age increases, the level of anxiety increases too. Teenage less than or equal to 19 had the lowest level of anxiety. This result may be explained by the fact that, it is commonly known that pregnancy is more dangerous when it occurs with old aged due to the possibility of occurrence of multiple complications. The literature indicates that some complications in pregnancy are associated with advanced maternal age. These include an increased risk for fetal loss, chromosome anomalies such as Down syndrome, multiple pregnancy, hypertension, diabetes, placenta previa, placental abruption, caesarean birth, preterm labor and low birth weight ${ }^{(43)}$. Furthermore, some studies have demonstrated an increased incidence of ante-partum hemorrhage, malpresentation and operative vaginal delivery $^{(44)}$.

Contrary to present study findings, Abiodun et al. (1993) in a study to determine psychiatric morbidity in pregnant population in Nigeria found significant association between mental health problems and primipara, aged less than 24 years as well as previous history of induced abortion $^{(45)}$. On the same line, another study performed by Rubertsson et al. (2014) to estimate the prevalence of maternal anxiety and associated factors in early pregnancy reported that, women aged less than 25 years were at an increased risk of anxiety symptoms during early pregnancy ${ }^{(46)}$. On the other hand, other studies reported that age did not affect psychological problem experienced such as anxiety and depression during pregnancy and post-partum $\operatorname{period}^{(5,47)}$.

Regarding educational level, a significant association was found between level of education and anxiety level. The less educated pregnant women had the highest level of anxiety compared to 
pregnant women with highest education. This finding is consistent with others studies' findings which reported that, women with a low level of education showed symptoms of anxiety and depression more often than those with a high level of education ${ }^{(30,48)}$. This could be explained by the fact that, they are less able to handle the demands and expectations placed on them during pregnancy ${ }^{(48,49)}$. In contrast, literate women may have good social networks and social support, which has been identified as a protective factor in previous research. Moreover, literacy gives individuals a sense of improved self-esteem or self-efficacy, enhances their feelings of self-worth, and diminishes feelings of shame. Hence it reduces depressive and anxiety symptoms ${ }^{(1,50-52)}$. On the other hand, another study highlighted education as a risk factor, explaining that highly educated individuals are more sensitive to and/or are not embarrassed about admitting depressive symptoms $^{(53)}$.

The type of family was identified as a significant socio-demographic risk factor for anxiety during pregnancy. The present study revealed that, the pregnant women who lived in extended families had higher level of anxiety more than pregnant women who lived in simple families. This finding concurred with relevant literature which reported that, the psychological pressures possibly created by authority figures in the traditional family structure like mother-inlaw and father-in-law may result in problems of self-expression and communication. Therefore, nuclear family type is more open to intra-familial communication and spouse relations are warmer in the nuclear family compared to extended family type. Accordingly, it was concluded that pregnant women living in nuclear families suffered anxiety less ${ }^{(5)}$.

The present study revealed that anxiety was higher among women with unwanted pregnancy followed by the presence of family problems during pregnancy. Different from the present study findings, a study by Akbaş (2006) suggested that desiring the baby is not associated with the state anxiety levels ${ }^{(54)}$. Similar to the present results, the study of Kaplan et al. (2007) and the study of Sertbaş G (1998) indicated that those who became involuntarily pregnant had higher state anxiety levels compared to those who had a wanted pregnancy ${ }^{(55,56)}$. Also, the study of Akbaş (2006) pointed out that those who were inharmonious with husbands had higher mean state anxiety scores $^{(54)}$. In contrast, the sociodemographic and obstetric characteristics in another study, found no significant difference and no association with the prevalence of mental health problem in terms of age, marital status, education level, occupation, family and maternal income, parity, gestational age, associated symptoms during current pregnancy and history of prior pregnancy ${ }^{(47)}$.

\section{Conclusion}

The present study confirms the presence of anxiety during pregnancy especially during first trimester followed by third trimester of pregnancy. It also revealed that age, educational level, family type, unwanted pregnancy and family problems are independent factors associated with the presence of anxiety.

\section{Recommendations}

Based on the findings of the present study, the following recommendations are suggested:

1- Screening by health care providers and psychologists must be done to detect anxiety symptoms among pregnant women since the first visit in antenatal clinic for early detection and dealing with these symptoms.

2- Special attention should be given from health care providers to all pregnant women who have risk factors as unwanted pregnancy, family problems and old age in 
order to protect them from increased level of anxiety and its negative effects.

3- Nurses working in maternal and child health care centers should provide the pregnant women with complete information about pregnancy, common changes that occur during it and sources of anxiety during that time and give special attention to women during first and third trimester.

4- Provide practical support to women during pregnancy through health care member by teaching them how to relieve anxiety by self expression or by relaxation techniques.

5- Family members should have an important role in providing psychological support for women during pregnancy to relieve their anxiety specially during first and third trimesters of pregnancy.

6- There is a need for greater research and clinical attention to be paid to antenatal anxiety and the adverse outcome on maternal well-being and fetal development. 


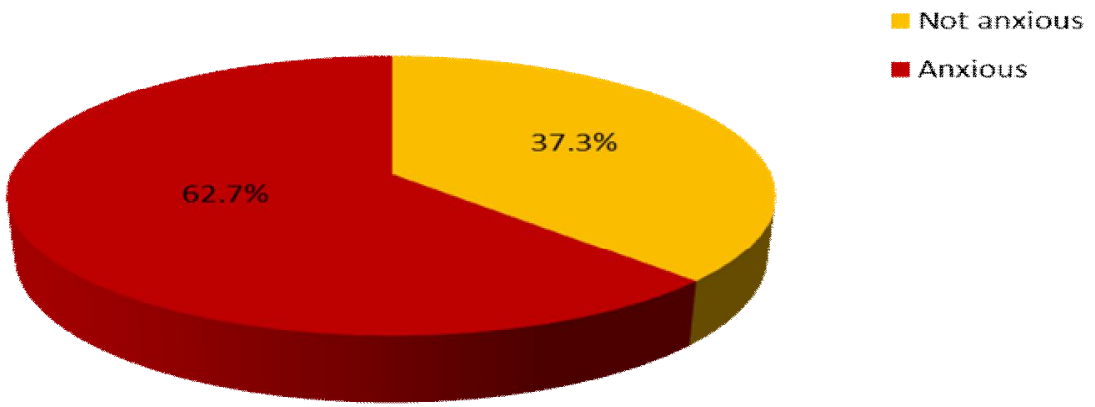

Figure (1): Anxiety among the total study subjects 
Table (1): Socio demographic characteristics of the studied subjects.

\begin{tabular}{|c|c|c|c|c|c|c|}
\hline \multirow{3}{*}{$\begin{array}{l}\text { Socio demographic } \\
\text { data }\end{array}$} & \multicolumn{4}{|c|}{ Anxiety } & \multirow{3}{*}{ Crude OR } & \multirow{3}{*}{ Adjusted OR } \\
\hline & \multicolumn{2}{|c|}{$\begin{array}{l}\text { Not anxious } \\
(\mathrm{n}=112)\end{array}$} & \multicolumn{2}{|c|}{ Anxious $(\mathrm{n}=188)$} & & \\
\hline & No & $\%$ & No & $\%$ & & \\
\hline \multicolumn{7}{|l|}{ Age (in years) } \\
\hline - $\leq 20$ & 20 & 50.0 & 20 & 50.0 & ref & ref \\
\hline - $20-$ & 75 & 36.9 & 128 & 63.1 & $1.7(0.8-3.4)$ & $2.8(1.2-5.4)^{*}$ \\
\hline - $30-$ & 17 & 29.8 & 40 & 70.2 & $2.4(1.1-5.5)^{*}$ & $3.9(1.7-9.9)^{*}$ \\
\hline \multicolumn{7}{|l|}{ Education } \\
\hline - Illiterate & 9 & 29.0 & 22 & 71.0 & $2.9(1.1-7.3)^{*}$ & $3.4(1.2-9.6)^{*}$ \\
\hline - Basic & 6 & 16.2 & 31 & 83.8 & $6.1(2.2-16.9)^{*}$ & $7.5(2.5-18.5)^{*}$ \\
\hline - Secondary & 65 & 37.6 & 108 & 62.4 & $1.9(1.1-3.6)^{*}$ & $2.4(1.2-4.8)^{*}$ \\
\hline - University & 32 & 54.2 & 27 & 45.8 & ref & ref \\
\hline \multicolumn{7}{|l|}{ Occupation } \\
\hline - House wife & 97 & 37.0 & 165 & 63.0 & ref & ref \\
\hline - Employer & 13 & 46.4 & 15 & 53.6 & $0.67(0.31-1.5)$ & $1.2(0.45-3.1)$ \\
\hline - Student & 2 & 20.0 & 8 & 80.0 & $2.4(0.49-11.3)$ & $4.0(0.78-20.4)$ \\
\hline \multicolumn{7}{|l|}{ Residence } \\
\hline - Rural & 52 & 34.2 & 100 & 65.8 & $1.3(0.82-2.1)$ & $1.1(0.59-1.7)$ \\
\hline - Urban & 60 & 40.5 & 88 & 59.5 & ref & ref \\
\hline \multicolumn{7}{|l|}{ Family type } \\
\hline - Nuclear & 64 & 43.2 & 84 & 56.8 & ref & ref \\
\hline - Extended & 48 & 31.6 & 104 & 68.4 & $1.7(1.1-2.6)^{*}$ & $1.5(0.89-2.6)$ \\
\hline
\end{tabular}


Table (2): Obstetric history of the studied subjects.

\begin{tabular}{|c|c|c|c|c|c|c|}
\hline \multirow{3}{*}{ Obstetric history } & \multicolumn{4}{|c|}{ Anxiety } & \multirow{3}{*}{ Crude OR } & \multirow{3}{*}{ Adjusted OR } \\
\hline & \multicolumn{2}{|c|}{$\begin{array}{c}\text { Not anxious } \\
(n=112)\end{array}$} & \multicolumn{2}{|c|}{$\begin{array}{c}\text { Anxious } \\
(n=188) \\
\end{array}$} & & \\
\hline & No & $\%$ & No & $\%$ & & \\
\hline \multirow{4}{*}{$\begin{array}{l}\text { Trimester of pregnancy } \\
\begin{aligned} & \text { - } \text { First trimester } \\
& \text { - } \text { Second trimester } \\
& \text { - } \text { Third trimester } \\
&\end{aligned}\end{array}$} & & & & & & \\
\hline & 31 & 31.0 & 69 & 69.0 & ref & ref \\
\hline & 41 & 41.0 & 59 & 59.0 & $1.5(1.0-2.6)^{*}$ & $0.68(0.36-1.3)$ \\
\hline & 40 & 40.0 & 60 & 60.0 & $1.0(0.55-1.6)$ & $0.59(0.3-1.0)^{*}$ \\
\hline \multirow{3}{*}{$\begin{array}{c}\text { Follow up of pregnancy } \\
\begin{array}{c}\text { - } \text { Yes } \\
\text { - } \text { No }\end{array}\end{array}$} & & & & & & \\
\hline & 110 & 37.0 & 187 & 63.0 & ref & ref \\
\hline & 2 & 66.7 & 1 & 33.3 & $0.29(0.03-3.2)$ & $0.45(0.1-5.1)$ \\
\hline \multicolumn{7}{|l|}{ Follow up place } \\
\hline - $\mathrm{MCH}$ center & 73 & 35.4 & 133 & 64.6 & $1.3(0.79-2.2)$ & $1.3(0.17-6.9)$ \\
\hline - Private doctor & 37 & 42.0 & 51 & 58.0 & ref & ref \\
\hline - General hospital & 0 & 0.0 & 3 & 100.0 & $1.2(0.47-5.9)$ & $1.3(0.25-4.8)$ \\
\hline \multicolumn{7}{|l|}{ Number of abortion } \\
\hline - None & 97 & 40.9 & 140 & 59.1 & ref & ref \\
\hline - 1 & 13 & 31.0 & 29 & 69.0 & $1.5(0.76-3.1)$ & $1.2(0.59-2.6)$ \\
\hline - 2 & 1 & 11.1 & 8 & 88.9 & $5.5(0.68-45.1)$ & $2.4(0.25-22.9)$ \\
\hline - $3+$ & 1 & 8.3 & 11 & 91.7 & $7.6(0.96-60.2$ & $6.1(0.76-49.8)$ \\
\hline \multicolumn{7}{|l|}{ Parity } \\
\hline - None & 67 & 46.2 & 78 & 53.8 & ref & ref \\
\hline - 1 & 26 & 32.1 & 55 & 67.9 & $1.8(1.1-3.2)^{*}$ & $1.5(1.0-2.8)^{*}$ \\
\hline - 2 & 16 & 30.8 & 36 & 69.2 & $1.9(1.0-3.7)^{*}$ & $1.6(0.76-3.2)$ \\
\hline - $3+$ & 3 & 13.6 & 19 & 86.4 & $5.4(1.5-20.0)^{*}$ & $3.4(0.89-13.2)$ \\
\hline \multicolumn{7}{|l|}{ Wanted pregnancy } \\
\hline - Yes & 109 & 39.5 & 167 & 60.5 & ref & ref \\
\hline - No & 3 & 12.5 & 21 & 87.5 & $4.5(1.3-15.6)^{*}$ & $3.3(1.0-12.2)^{*}$ \\
\hline \multicolumn{7}{|l|}{ Family problems } \\
\hline - Yes & 7 & 16.3 & 36 & 83.7 & $3.6(1.5-8.3)^{*}$ & $3.5(1.5-8.4)^{*}$ \\
\hline - No & 105 & 40.9 & 152 & 59.1 & ref & ref \\
\hline
\end{tabular}

N.B. 2 subjects did not make any follow up for their pregnancy at any place. 
Table (3): Results of multiple stepwise logistic regression model for risk factors of anxiety.

\begin{tabular}{|c|c|c|c|c|c|c|}
\hline \multirow{2}{*}{ Factor } & \multirow{2}{*}{ B } & \multirow{2}{*}{ S.E. } & \multirow{2}{*}{$\mathbf{P}$} & \multirow{2}{*}{ OR } & \multicolumn{2}{|c|}{ 95.0\% C.I for OR } \\
\hline & & & & & Lower & Upper \\
\hline $\begin{array}{l}\text { Unwanted } \\
\text { pregnancy }\end{array}$ & 1.37 & 0.66 & 0.037 & $3.92 *$ & 1.08 & 14.19 \\
\hline $\begin{array}{l}\text { family problems } \\
\text { Age (in years) }\end{array}$ & 1.36 & 0.45 & 0.003 & $3.91 *$ & 1.61 & 9.52 \\
\hline $20-29$ & 0.93 & 0.39 & 0.016 & $2.53 *$ & 1.18 & 5.39 \\
\hline $30-39$ & 1.17 & 0.49 & 0.016 & $3.23 *$ & 1.25 & 8.38 \\
\hline Education & & & & & & \\
\hline Illiterate & 1.00 & 0.50 & 0.046 & $2.73 *$ & 1.02 & 7.28 \\
\hline Basic & 1.74 & 0.55 & 0.001 & $5.68 *$ & 1.95 & 16.57 \\
\hline Secondary & 0.70 & 0.33 & 0.031 & $2.02 *$ & 1.06 & 3.82 \\
\hline Extended family & 0.56 & 0.27 & 0.036 & $1.75 *$ & 1.04 & 2.96 \\
\hline Constant & -1.53 & 0.49 & 0.002 & 0.22 & & \\
\hline $\begin{array}{l}\text { Model } \\
\text { significance }\end{array}$ & \multicolumn{6}{|c|}{$\mathrm{X}^{2}=42.4 ; \mathrm{P}<0.001 *$} \\
\hline $\begin{array}{l}\text { Classification } \\
\text { accuracy }\end{array}$ & \multicolumn{6}{|c|}{$71.0 \%$} \\
\hline
\end{tabular}

B. Regression coefficient $\quad$ S.E. Standard error

P. P value $<0.005 \quad$ OR: Odis ratio 


\section{References}

1. Nasreen H, Kabir Z, Forsell Y, Edhborg $M$. Prevalence and associated factors of depressive and anxiety symptoms during pregnancy: a population based study in rural Bangladesh. Bio Med Central Women's Health 2011; 11-22.

2. Mina SH, Balhara Y, Verma R, Mathur SH. Anxiety and Depression amongst the urban females of Delhi in antepartum and post-partum period. Delhi Psychiatry Journal 2012; 15 (2): 347-51.

3. Bussel J, Spitz B, Demyttenaere K. Anxiety in pregnant and postpartum women. An exploratory study of the role of maternal orientations. Journal of Affective Disorders 2009; 114: 232-42.

4. Chan $\mathrm{CH}$, Lee $\mathrm{A}$, Lam $\mathrm{S}$, Lee $\mathrm{CH}$, Leung K, Koh Y, Tang C. Antenatal anxiety in the first trimester: risk factors and effects on anxiety and depression in the third trimester and 6-week postpartum. Open Journal of Psychiatry 2013; 3: 301-10.

5. Duman N. Socio-demographic and obstetric factors associated with depression during pregnancy in turkey. American International Journal of Contemporary Research 2012; 2 (11): 17-26.

6. Singh S. Level of anxiety among prospective teachers. Journal of SPIJE 2011; 1 (1): 17-21.

7. Acaroğlu R, Kaya H, Şendir M, Tosun $\mathrm{K}$, Turan Y. Levels of anxiety and ways of coping of family members of patients hospitalized in the neurosurgery intensive care unit. Journal of Neurosciences 2008; 13 (1): 41-5.

8. Trait and state anxiety. State of New South Wales, Department of Education and Communities and Charles Sturt University, 2014. Available at: http://www.hsc.csu.edu.au/pdhpe/core2/ focus $2 /$ focus $2 / 4021 /$ fac $22221 . \mathrm{htm}$
9. Yonkers KA, Ramin SM, Rush AJ, Navarrete CA, Carmody T, March D, Heartwell SF, Leveno KJ. Onset and persistence of postpartum depression in an inner-city maternal health clinic system. American Journal of Psychiatry 2001; 158(11):1856-63.

10. Karmaliani R, Asad N, Bann CM, Moss N, Mcclure EM, Pasha O, Wright LL, Goldenberg RL. Prevalence of anxiety, depression and associated factors among pregnant women of Hyderabad, Pakistan. International Journal of Social Psychiatry 2009; 55 (5): 414-24.

11. Heron J, O'Connor TG, Evans J, Golding J, Glover V, ALSPAC Study Team. The course of anxiety and depression through pregnancy and the postpartum in a community sample. Journal of Affective Disorders 2004; 80(1): 65-73.

12. Faisal-Cury A, Menezes R. Prevalence of anxiety and depression during pregnancy in a private setting sample. Archives of Women's Mental Health 2007; 10(1):25-32.

13. Lee AM, Lam SK, Lau SM, Chong CS, Chui HW, Fong DY. Prevalence, course, and risk factors for antenatal anxiety and depression. Journal of Obstetric Gynecology 2007; 110(5):1102-12.

14. Andersson L, Sundström-Poromaa I, Bixo M, Wulff M, Bondestam K, åStröm M. Point prevalence of psychiatric disorders during the second trimester of pregnancy: a populationbased study. American Journal of Obstetrics and Gynecology 2003; 189(1):148-54.

15. Halbreich U. Prevalence of mood symptoms and depressions during pregnancy: implications for clinical practice and research. Journal of CNS Spectrums 2004; 9(3):177-84.

16. Teixeira C, Figueiredo B, Conde A, Pacheco A, Costa R. Anxiety and 
depression during pregnancy in women and men. Journal of Affective Disorders 2009; 119: 142-48.

17. Madhavanprabhakaran G, Kumar K. A., Ramasubramaniam SH, Akintola A. Effects of pregnancy related anxiety on labour-outcomes: a prospective cohort study. Journal of Research in Nursing and Midwifery 2013; 2(7): 96-103.

18. Buist A, Gotman N, Yonkers KA. Generalized anxiety disorder: course and risk factors in pregnancy. Journal of Affective Disorders 2011; 131(1-3): 277-83.

19. El-Gharib M.N., Rakha S.F., Awara A.M., Mahfouz A.E., Elhawary T.S. Causes of maternal deaths in Tanta university hospital. Journal of Clinical Medicine Reviews in Women's Health 2010; 2: 79-83.

20. Sawyer A, Ayers S, Smith H. Pre-and postnatal psychological wellbeing in Africa: a systematic review. Journal of Affective Disorders 2010; 123(1-3):1729.

21. Bennett HA, Einarson A, Taddio A, Koren G, Einarson TR. Prevalence of depression during pregnancy: systematic review. Journal of Obstetrics and Gynecology 2004; 103(4):698-709.

22. Roos A, Faure S, Lochner C, Vythilingum B, Stein DJ. Predictors of distress and anxiety during pregnancy. African Journal of Psychiatry 2013; 16: 118-22.

23. Khalajzadeh M, Shojaei M, Mirfaizi M. The effect of yoga on anxiety among pregnant women in second and third trimester of pregnancy. European Journal of Sports and Exercise Science 2012; 1 (3): 85-9.

24. Arch J. Pregnancy-specific anxiety: which women are highest and what are the alcohol-related risks?. Journal of Comprehensive Psychiatry 2012; $\mathrm{xx}$ : $\mathrm{xxx}-\mathrm{XxX}$.
25. Schetter CH, Tanner L. Anxiety, depression and stress in pregnancy: implications for mothers, children, research, and practice. Journal of Behavioural medicine 2012; 25(2): 141 48.

26. A guide to emotional health and well being during pregnancy and early parenthood. Available at: www.beyondblue.org.au

27. Lee I, Ho L, Ma G, Leung W. The effect of a birth plan on anxiety levels in Chinese pregnant women: a randomized controlled trial. Journal of Gynecology and Obstetrics Midwifery 2010; 10:326.

28. Melender HL. Experiences of fears associated with pregnancy and childbirth: a study of 329 pregnant women. Journal of Birth 2002; 29(2):101-11.

29. Melender HL, Lauri S. Fears associated with pregnancy and childbirth-experiences of women who have recently given birth. Journal of Midwifery 1999; 15(3):177-82.

30. Hussein SH. Anxiety during pregnancy among Sudanese pregnant women. Sudan JMS 2006; 1(2): 127-31.

31. Haring M, Smith J, Bodnar D, Misri SH, Little R, Ryan D. Coping with anxiety during pregnancy and following the birth. A cognitive behavior therapybased self-management guide for women and health care providers. BC Mental Health and Addiction Services. 2013.

32. Logsdon MC, Birkimer JC, Simpson T, Looney S. Postpartum depression and social support in adolescents. Journal of Obstetric, Gynecologic Neonatal Nursing 2005; 34(1):46-54.

33. Gurung R, Schetter CH, Collins N, Rini $\mathrm{CH}$, Hobel C. Psychosocial predictors of prenatal anxiety. Journal of Social and Clinical Psychology 2005; 24(4): 497-519. 
34. Cenksoy P. The determination of prenatal and early postnatal anxiety level and identification of predisposing factors for high anxiety level. Journal of Women's Health Care 2013; 2(4):1-3.

35. Fertl KI, Bergner A, Beyer R, Klapp BF, Rauchfuss M. Levels and effects of different forms of anxiety during pregnancy after a prior miscarriage. European Journal of Obstetrics Gynecology and Reproductive Biology 2009; 142(1):23-9.

36. Ryan A. Interventions to reduce anxiety during pregnancy: an overview of research. Perspective - NCT's journal on preparing parents for birth and early parenthood. 2013: 16-20.

37. Huang Z, Hao J, Su P, Huang K, Xing X, Cheng D, Xiao L, Xu Y, Zhu X, Tao F. The impact of prior abortion on anxiety and depression symptoms during a subsequent pregnancy: data from a population-based cohort study in China. Bulletin of Clinical Psychopharmacology 2012; 22(1):51-8.

38. Schetter D. Psychological science on pregnancy: stress processes, biopsychosocial models, and emerging research issues. Annual Review of Psychology 2011; 62:531-58.

39. Spielberger CD: Manual for the StateTrait anxiety inventory Palo Alto, California: Consulting Psychologists Press; 1983.

40. Abdel-Khalek A. The development and validation of an Arabic form of the STAI: Egyptian results. Journal of Personality and Individual Differences 1989; 10 (3): 277-85.

41. Altınay, S. (1999). Gebelikte depresyon prevalansı. sosyodemografik özellikler. obstetrik risk faktörleri. kaygı düzeyi ve sosyal destek ile ilişkisi. Master Thesis, T.C. Ministry of Health Ankara Hospital, Ankara Turkey. In: Duman N. Socio-demographic and obstetric factors associated with depression during pregnancy in turkey. American International Journal of Contemporary Research 2012; 2 (11): 17-26.

42. Kelly R, Russo J, Katon W. Somatic complaints among pregnant women cared for in obstetrics: normal pregnancy or depressive and anxiety symptom amplification revisited? Journal of General Hospital Psychiatry 2001; 23(3): 107-13.

43. Main D, Main E, Moore D. The relationship between maternal age and uterine dysfunction: a continuous effect throughout reproductive life. American Journal of Obstetrics and Gynecology 2000; 182:1312-20.

44. Jolly M, Sebire N, Harris J, Robinson S, Regan L. The risks associated with pregnancy in women aged 35 years or older. Oxford Journals 2000; 15(11): 2433-37.

45. Abiodun O, Adetoro O, Ogunbode O. Psychiatric morbidity in a pregnant population in Nigeria. Journal of General Hospital Psychiatry 1993; 15(2) 125-8.

46. Rubertsson C, Hellström J, Cross M, Sydsjö G. Anxiety in early pregnancy: prevalence and contributing factors. Journal of Archives of Women's Mental Health 2014; 17(3): 221-8.

47. Wingwontham S, Thitadilok W, Singhakant S. Prevalence of mental health problem during first-half pregnancy at Siriraj hospital. Journal of the Medical Association of Thailand 2008; 91 (4): 452-7.

48. Claesson I, Josefsson A, Sydsjö G. Prevalence of anxiety and depressive symptoms among obese pregnant and postpartum women: an intervention study. Journal of BioMed Central 2010; 10 (766):1-10.

49. Britton J. Maternal anxiety: course and antecedents during the early postpartum period. Journal of Depression and Anxiety 2008; 25(9): 793-800. 
50. Dennis C-L, Hodnett E, Kenton L, Zupancic J, Stewart DE, Kiss A: Effect of peer support on prevention of postnatal depression among risk women: multisite randomized controlled trial. British Medical Journal 2009; 338 (7689): 1-9.

51. Francis L, Weiss BD, Senf JH, Heist K, Hargraves R. Does literacy education improve symptoms of depression and self-efficacy in individuals with low literacy and depressive symptoms? a preliminary investigation. Journal of the American Board of Family Medicine 2007; 20(1): 23-7.

52. Weiss BD, Francis L, Senf JH, Heist K, Hargraves R. Literacy education as treatment for depression in patients with limited literacy and depression: a randomized controlled trial. Journal of General Internal Medicine 2006; 21(8):823-8.

53. Zimmerman FJ, Katon W. Socioeconomic status, depression disparities, and financial strain: what lies behind the income-depression relationship? Journal of Health Economics 2005; 14(12):1197-215.

54. Akbaş, E. (2006). Gebe kadınlarda depresyon ve anksiyete düzeylerinin sosyal destek ile ilişkisi. Master Thesis, Gaziantep University Health Sciences Institute, Gaziantep Turkey. In: Duman N. Socio-demographic and obstetric factors associated with depression during pregnancy in turkey. American International Journal of Contemporary Research 2012; 2 (11): 17-26.

55. Kaplan S, Bahar A, \& Sertbaş G. (2007). Gebelerde doğum öncesi ve doğum sonrası dönemlerde durumluk kayg1 düzeylerinin incelenmesi. Atatürk Üniversitesi Hemşirelik Yüksekokulu Dergisi, 10(1), 113-121. In: Duman N. Socio-demographic and obstetric factors associated with depression during pregnancy in turkey. American International Journal of Contemporary Research 2012; 2 (11): 17-26.

56. Sertbaş G. (1998). Gebelerde doğum öncesi ve doğum sonrası dönemlerde durumluk- sürekli kaygı düzeylerinin incelenmesi. Türk Hemşireler Dergisi, 48(6), 16-19. In: Duman N. Sociodemographic and obstetric factors associated with depression during pregnancy in turkey. American International Journal of Contemporary Research 2012; 2 (11): 17-26. 